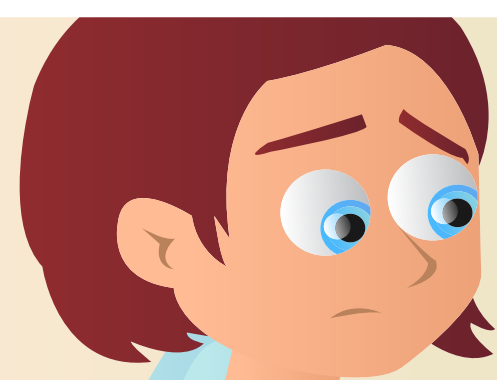

\title{
WHY BABIES BORN EARLY CAN BE REALLY SICK
}

\section{Jessie Newville ${ }^{1}$, Maria C. Ortega ${ }^{2}$ and Jessie R. Maxwell ${ }^{2 *}$}

${ }^{1}$ Department of Neurosciences, University of New Mexico, Albuquerque, NM, United States, ${ }^{2}$ Department of Pediatrics, University of New Mexico, Albuquerque, NM, United States

\section{REVIEWED BY:}

CHLOE 14 YEARS OLD

\section{PRE-TERM}

A baby that is born before being inside the mother for 37 weeks.

\section{EXTREMELY PRE-TERM}

A baby that is born before being inside the mother for 28 weeks.
The human body is really complex. Different parts of the body form before and after birth. Sometimes babies are born early. When babies are born early, they can be very sick because their bodies have not finished forming. Doctors take special care of these babies to help them live and grow. To make these babies better, it is important to understand what is making them sick. Babies who are born early can have problems with important parts of their body such as their brain, eyes, lungs, heart, and intestines. Doctors and scientists work together to learn more about what is making these babies sick and to figure out how to help them so that these babies can grow up to be kids who can run, play, and do well in school.

\section{INTRODUCTION}

A normal human pregnancy lasts $37-40$ weeks. The whole time that the baby is inside of the mother, the different parts of the baby's body are forming. Sometimes, babies are born before 37 weeks. Doctors call these babies who are born early "pre-term." A baby born before 28 weeks is considered "extremely pre-term." When babies are born early they can be very sick. Every year, around 15 million babies are born pre-term, which makes up about $11 \%$ of 
CEREBROSPINAL

FLUID

A clear fluid that flows through the ventricles of the brain and the spinal cord. This fluid is important because it provides cells with nutrients, removes waste, and helps protect the brain from damage during an impact.

\section{FIGURE 1}

This figure points to some important parts of a baby's body that are injured when they are born early. Intraventricular hemorrhage can happen in the brain of pre-term babies. Retinopathy of prematurity is a condition that pre-term babies can develop in their eyes. Bronchopulmonary dysplasia is a problem that pre-term babies can have with their lungs. Patent ductus arteriosus is a problem with the heart that pre-term babies can have. Pre-term babies can also become sick if they have a condition in their intestines called necrotizing enterocolitis. all births worldwide [1]. The United States has one of the highest numbers of pre-term births in the world [1]. This means that the United States also has one of the highest numbers of babies who might be sick from being born early.

Organs are body parts that do important jobs to keep us alive. All of the organs inside of a baby's body are affected when a baby is born early. Babies can be very sick if their organs do not form normally and cannot do their jobs. When pre-term babies grow up, they might have problems using their brains to learn or using their lungs to breathe. This article explains a few of the main health problems with the brain, eyes, lungs, heart, and intestines that pre-term babies can have (Figure 1). Doctors have really long names for these problems in the different parts of the body. When doctors talk about these health problems, they might use the full name or just the abbreviation, so it is important to be familiar with both.

\section{BRAIN}

The brain is the incredible organ in your head that thinks thoughts and tells your body how to move. People can have problems for the rest of their lives if the brain is injured when it is still forming. There is an area inside of a baby's brain where bleeding can happen if the baby is born early [2]. The blood vessels in that area are very weak. Little changes in the blood flow or in the blood pressure can cause those vessels to break open and bleed. When these vessels break open, blood escapes into the ventricles. Ventricles are tunnels in the brain that are normally filled with a clear liquid called "cerebrospinal fluid." This fluid carries important material to brain cells and also removes waste products. When blood fills the ventricles, making them bigger than normal, doctors diagnose a baby with what is called an "intraventricular hemorrhage" (IVH) (Figure 2A). The cells that make up the brain are not supposed to be in contact with blood. When blood enters the ventricles and touches these cells, they can start to die and that causes damage to the brain. More parts of the brain will be damaged if there is a lot of blood in the ventricles.

When brain tissue is damaged and starts to break down, it affects how the brain is formed in that area. Brain areas that control how the body moves are

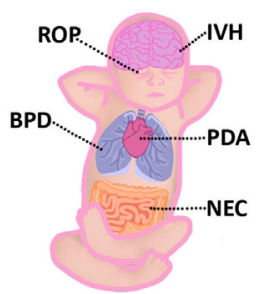

FIGURE 


\section{FIGURE 2}

Babies who are born early can have problems inside of their brains and eyes that make them sick.

(A). Two brain images, one of a normal healthy baby and one of a baby with intraventricular hemorrhage (IVH). In this image, you are looking at a slice through the middle of the brain. The ventricles (blue, Y-shaped structure) in the normal brain are filled with clear liquid called cerebrospinal fluid (blue). A baby has IVH if bleeding in the brain occurs that fills the ventricles with blood (red). As the figure shows, the bleeding increases the amount of fluid in the ventricles, making them larger than normal. The bleeding also damages the surrounding brain tissue. (B). This is an image of two whole eyes outside of the head from the side. The eye on the left shows the normal structure, including the retina and blood vessels.

The eye on the right illustrates retinopathy of prematurity and shows how the blood vessels look when they develop abnormally and how the retina looks when it becomes detached.

\section{CEREBRAL PALSY}

A disorder that can happen when babies who are born early have brain injury. As they grow up, they cannot move their arms and legs normally and sometimes cannot walk.

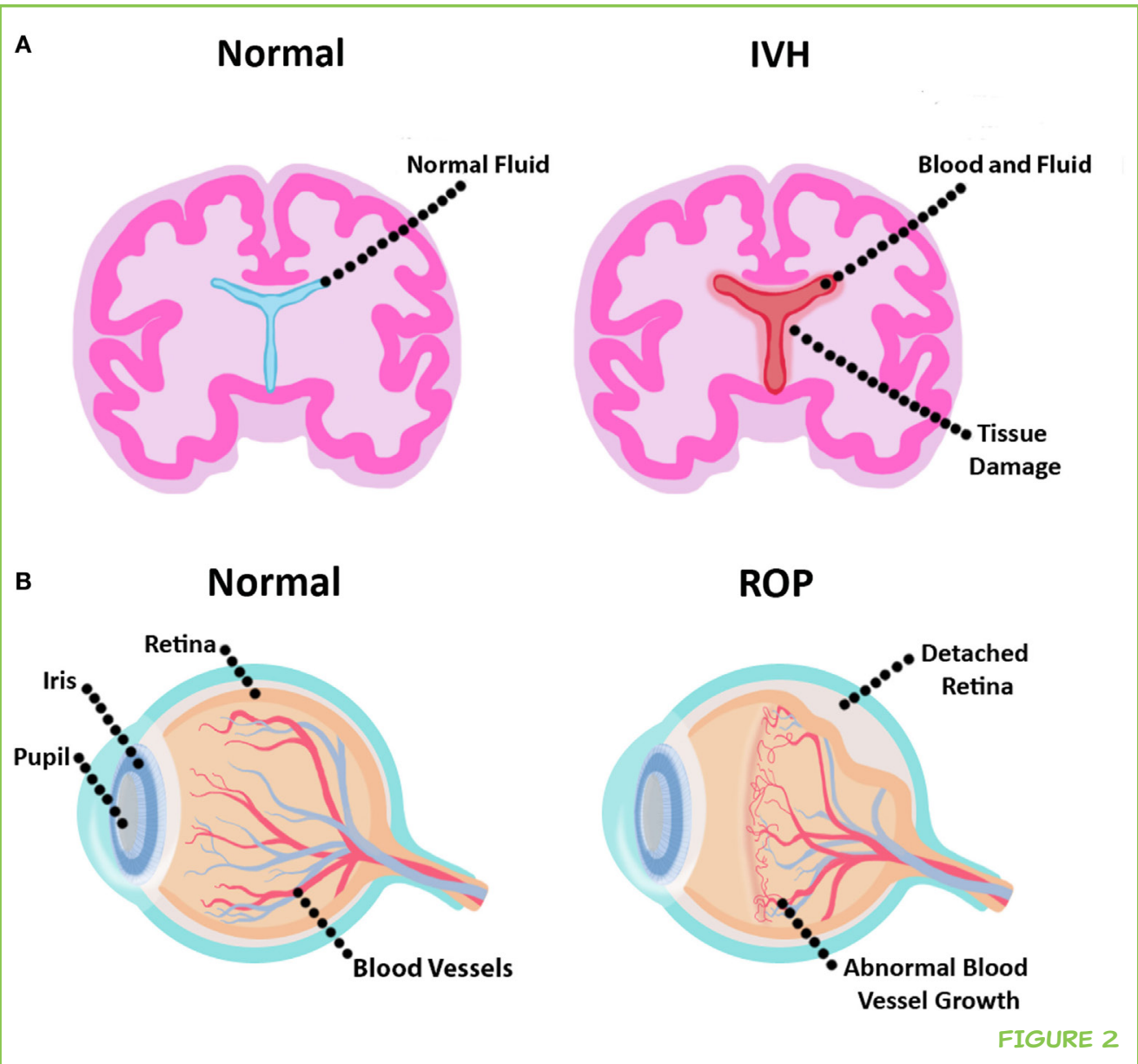

commonly damaged in babies who have IVH. These babies are diagnosed with a condition called "cerebral palsy." These babies have difficulty controlling their muscle movements. The brain injury that causes cerebral palsy makes it hard for people with cerebral palsy to walk and talk when they grow up. Other areas of the brain can also be damaged in pre-term babies with IVH. When these babies grow up, they might have trouble using their brains to focus in school.

The earlier a baby is born, the higher the risk for IVH because of how much the brain still needs to form. When bleeding happens in the ventricles, doctors will watch to see how much bleeding there is and how much tissue is damaged. Depending on what they see, doctors will recommend that the baby receive extra help as he or she grows up.

\section{EYES}

Eyes are so cool! We use them every day to see the wonderful world around us. Pre-term babies can have eye problems because the eyes are not fully formed when they are born. The blood vessels in the back of the eyes are 
still forming when a baby is born early. The blood vessels in the eyes grow based on the amount of oxygen that touches them. Before a baby is born, the eyes are not exposed to very much oxygen. When a baby is born early, the eyes are exposed to a greater amount of oxygen before they are ready. The higher level of oxygen causes the blood vessels of the eye to stop growing as they normally would and to grow incorrectly. If the vessels grow in the wrong ways, the baby can develop a sickness called "retinopathy of prematurity" (ROP) (Figure 2B).

Retinopathy of prematurity can cause serious damage to the eyes if not treated. The worst-case scenario is that, if the vessels grow incorrectly, the retina could separate from the back of the eye. The retina is a layer of cells that lies against the back of the eye and is important for seeing. If the retina detaches from the back of the eye, then the eye will not be able to work and the baby will be blind. ROP is a leading cause of blindness in kids. Doctors recommend that pre-term babies that are born earlier than 30 weeks or weigh less than $1,500 \mathrm{~g}$ at birth should have eye exams to monitor how the blood vessels in the eyes are growing [3].

If a doctor diagnoses a baby with ROP, the doctor can help prevent blindness by burning the bad blood vessels growing in the eye with a laser. The baby will not be able to see well from the sides of the eye, but they will still be able to see from the center of the eye. Right now there are not many treatment options that doctors can choose from to help babies with ROP. It is important to learn more about ROP so that doctors can develop new ways to help these babies.

\section{DIAGNOSIS}

What doctors do when they decide, based on the symptoms that are making a person sick, which condition the person likely has.

\section{SURFACTANT}

A substance made by the body that coats the inside of the lungs. It makes it easier for a person to breathe in and out.

\section{LUNGS}

When we breathe in, we fill our lungs with oxygen. It is really important that our lungs work well, because they are the organs in charge of getting our bodies the oxygen we need to survive. Babies who are born early can have trouble breathing because their lungs are not ready to breathe in and out. If a pre-term baby has breathing problems, doctors give the baby the "diagnosis" of "bronchopulmonary dysplasia" (BPD). Half of extremely pre-term babies have breathing problems and are diagnosed with BPD [4].

One reason that babies born early have difficulty breathing is because they lack a substance in the lungs called "surfactant." Surfactant is a fatty substance that coats the inside of the lungs. This special substance, made by the body, allows the lungs to move easier. When there is enough surfactant, the lungs can easily get bigger (while breathing in) and get smaller (while breathing out). A person has to breathe to deliver oxygen to the body. The body starts to make surfactant in the lungs around 34 weeks into the pregnancy, so that when the baby is born on time, the lungs will be ready to breathe on 
DUCTUS ARTERIOSUS

Before babies are born, they have a tunnel near their heart that helps more blood to flow into their bodies instead of flowing into their lungs. After birth, this tunnel is supposed to close. their own. Pre-term babies are born before their bodies have made enough surfactant. This makes it hard for their lungs to move and hard for oxygen to make it to the cells in the body that need it. In the early 1990s, scientists were able to make artificial surfactant that doctors could give babies. The artificial surfactant helps pre-term babies breathe more easily [4]. This medicine has greatly improved the lives of babies born early and shows how important it is to support medical research.

\section{HEART}

The heart is the organ responsible for pumping blood. The blood carries important materials like oxygen to cells in different parts of the body. Before a baby is born, the baby receives oxygen from the mother's blood. Because a baby inside of the mother does not use their lungs to receive oxygen, the heart decreases blood flow to the lungs. The structure of the heart changes when a baby is born, sending more blood flow to the lungs. The part of the heart that makes the blood flow to the body instead of the lungs is a tunnel called the "ductus arteriosus." When a baby is born on time, this structure closes in the first few days of life, as the baby starts to use their lungs for breathing. When babies are born early, this structure can stay open for a longer period of time and cause trouble. When the ductus arteriosus stays open for too long, it is called a "patent ductus arteriosus" (PDA) (Figure 3A). A PDA causes blood to flow back and forth across it, based on the pressures on either side. The issue with a PDA is that it can sometimes let too much blood flow into the lungs. When there is excess blood in the lungs it is harder too much to breathe.

The change in blood flow caused by a PDA is a serious problem for preterm babies. Doctors can use medications or perform surgery to close the PDA. The medicine that doctors give babies to close a PDA works by stopping the body from making fatty molecules, called "prostaglandins," that keep the PDA open. This medicine works better when given early in life. Unfortunately, this medicine does not always close the PDA. Doctors have to be careful when giving this medicine to babies because they know that it can have bad side effects on the other developing organs. When the medicine does not work and the baby still has trouble breathing, doctors can choose to perform surgery to close the PDA. Surgery guarantees that the tunnel is closed, but the procedure is hard on the baby's body.

\section{INTESTINES}

When we eat food, it passes through an organ in the body called the intestines. The intestines are important for taking the nutrients that our bodies need to grow out of the food we eat. Sometimes when a pre-term baby is 


\section{FIGURE 3}

Pre-term babies can become sick from problems with their hearts and intestines. (A). Two

hearts are shown cut open down the middle, to show how blood flows through the different compartments. In this illustration, the blood carrying oxygen from the lungs is red, and the blood without oxygen coming back to the heart from the body is blue. The heart on the left shows the normal flow of blood. Pre-term babies can have a tunnel in their hearts called a patent ductus arteriosus. The blood flowing through this opening can carry oxygen or not (purple arrows) and can change direction. (B). X-rays of normal intestines and the intestines of a baby with necrotizing enterocolitis (NEC). As you can see by comparing these $\mathrm{X}$-rays, the abdomen of the baby with NEC is larger because it is swollen. Doctors can use X-rays to help diagnose NEC, because $\mathrm{X}$-rays allow them to see different features inside of the intestines. Babies who develop NEC have little air bubbles in their intestines called pneumatosis intestinalis.

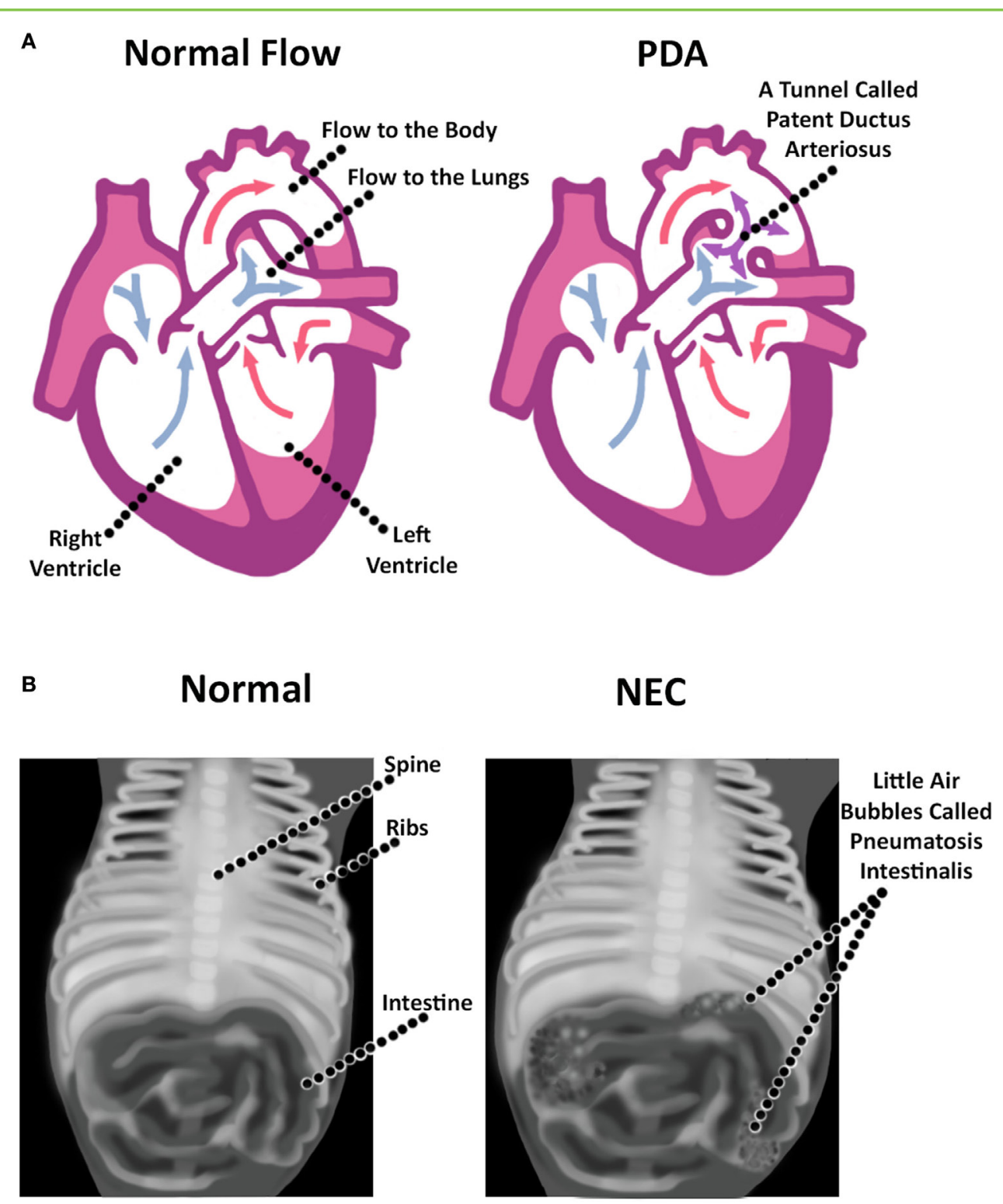

FIGURE 3

born, their intestines can become unhealthy. If the baby's intestines become swollen and start to die, a doctor will diagnose the baby with a condition called "necrotizing enterocolitis" (NEC). NEC is difficult for doctors to treat, because they are not exactly sure what causes it. The chances of having NEC increases the earlier a baby is born. Five to ten percent of extremely pre-term babies are diagnosed with NEC [5].

A baby who has NEC might experience vomiting, blood in the feces (poop), excessive sleepiness, or a swollen belly. Babies with NEC can get really sick and may need help with their breathing. They also might have trouble making a certain type of blood cell that helps to make blood clots, which work to stop bleeding. When a doctor takes an X-ray of a baby with NEC, they can see little bubbles in the walls of the intestines. Doctors call these 


\section{INFLAMMATION}

When a part of the body is infected or injured, molecules are released in that area to help the body heal. These molecules can make the tissue look red and swollen.

bubbles "pneumatosis intestinalis," and they think that the bubbles come from bacteria in the intestine that make air pockets, as shown in Figure $3 \mathrm{~B}$. When a baby is very sick from NEC, doctors may see holes in the walls of the baby's intestines.

Sometimes doctors perform surgery to remove the parts of the intestine that have died or have been damaged by holes. In some cases, other parts of the intestine are able to complete the job of the intestine that was removed, but not always. If what's left of the intestine cannot do the job of the part that was removed, the baby can have trouble getting the nutrients that the body needs. If the body does not have enough nutrients, the baby will not be able to grow. Because doctors do not know exactly what causes NEC, they have not found a good treatment to fix the problem. Babies with NEC are given "supportive care," which means that they receive medicine that seems to help them feel better. They also receive help with any other health issues that come up. Babies do not eat when they have NEC, because the intestines are not healthy. Because doctors think that the bubbles that show up in the X-rays are made by bacteria, doctors give these babies antibiotic medicine that kills the bacteria. Babies with NEC can have problems breathing, because their lungs are squashed from the swelling in the abdomen. These babies usually need help breathing until their intestines get better. Babies with NEC are at risk for developing scars in their intestines from the inflammation they experience. Between 10 and 35\% of babies with NEC will develop scars in their intestines and may vomit too much when they are older and not get the nutrients their bodies need [5].

\section{CONCLUSION}

Babies who are born early still have a lot of organ formation to complete. Unfortunately, when a baby is born early their organs could develop abnormally. The health problems that we talked about in this article occur at different times after a baby is born. IVH and PDA usually occur or cause problems during the first few weeks of life, followed by NEC and ROP as the baby becomes older. BPD is typically diagnosed after a month of age if a baby continues to have trouble with breathing. IVH, ROP, BPD, PDA, and NEC are common health problems in pre-term babies. Each problem can be mild or severe. NEC is the most life threatening of these problems, because once too much of the intestine has died there are not any treatments that can cure these babies. PDA is not life threatening alone but can hurt other organs if these organs do not receive the oxygen they need to be healthy. When BPD is severe, it can be life threatening, because these babies cannot breathe on their own. ROP is the least life threatening but still very serious, because it causes blindness. Doctors try their hardest to keep pre-term babies alive and healthy. They continue to work toward finding the best ways to help each baby. 


\section{REFERENCES}

1. Blencowe, H., Cousens, S., Oestergaard, M. Z., Chou, D., Moller, A. B., Narwal, R., et al. 2012. National, regional, and worldwide estimates of preterm birth rates in the year 2010 with time trends since 1990 for selected countries: a systematic analysis and implications. Lancet 379(9832):2162-72. doi:10.1016/S01406736(12)60820-4

2. Volpe, J. J. 2008. Neurology of the Newborn. 5th ed. (Vol. xiv). Philadelphia, PA: Saunders/Elsevier. 1094 p.

3. Fierson, W. M., and American Academy of Pediatrics Section on Ophthalmology, American Academy of Ophthalmology, American Association for Pediatric Ophthalmology and Strabismus, American Association of Certified Orthoptists. 2013. Screening examination of premature infants for retinopathy of prematurity. Pediatrics 131(1):189-95. doi:10.1542/peds.2012-2996

4. Owen, L. S., Manley, B. J., Davis, P. G, and Doyle, L. W. 2017. The evolution of modern respiratory care for preterm infants. Lancet 389(10079):1649-59. doi:10.1016/S0140-6736(17)30312-4

5. Gleason, C. A., Devaskar, S. U, and Avery, M. E. 2012. In: Christine AG, Sherin UD editors. Avery's Diseases of the Newborn. 9th ed. (Vol. xx), Philadelphia, PA: Saunders/Elsevier. 1498 p.

SUBMITTED: 06 June 2017; ACCEPTED: 04 October 2017; PUBLISHED ONLINE: 25 October 2017.

EDITED BY: Fulvio D'Acquisto, Queen Mary University of London, United Kingdom

CITATION: Newville J, Ortega MC and Maxwell JR (2017) Why Babies Born Early Can Be Really Sick. Front. Young Minds 5:60. doi:10.3389/frym.2017.00060

CONFLICT OF INTEREST STATEMENT: The authors declare that the research was conducted in the absence of any commercial or financial relationships that could be construed as a potential conflict of interest.

COPYRIGHT @ 2017 Newville, Ortega and Maxwell. This is an open-access article distributed under the terms of the Creative Commons Attribution License (CC BY). The use, distribution or reproduction in other forums is permitted, provided the original author(s) or licensor are credited and that the original publication in this journal is cited, in accordance with accepted academic practice. No use, distribution or reproduction is permitted which does not comply with these terms.

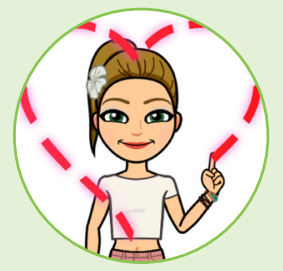

\section{REVIEWED BY}

\section{CHLOE, 14 YEARS OLD}

I am a freshman in high school this year. I like math and science. I hope to be a doctor when I grow up. I love to ski and play soccer. I like to travel, my favorite places have been Italy and Kenya. I also love spending time with my family and friends. 


\section{AUTHORS}

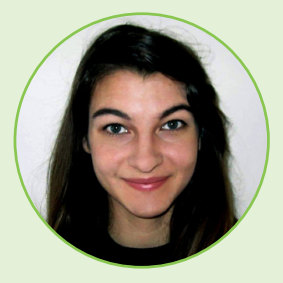

\section{JESSIE NEWVILLE}

Jessie Newville is a researcher in the Neurosciences Department at the University of New Mexico. She loves learning about all things oligodendrocyte related; oligodendrocytes are a unique type of cell found in the brain. Her current research investigates how exposure to alcohol during development results in acute and long lasting brain injury. Through her research, she contributes to the larger effort in the development of therapies that help people who have fetal alcohol spectrum disorder. When she has free time, she explores New Mexico, gardens, and appreciates poetry.

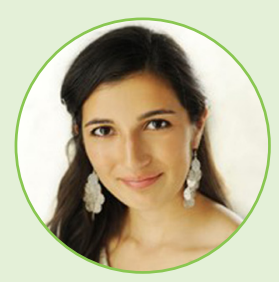

\section{MARIA C. ORTEGA}

Maria C. Ortega graduated from the University of New Mexico (UNM) with a B.S. in psychology. She has contributed to the research efforts of Dr. Lauren Jantzie at the UNM Health Sciences center who investigates brain injury that occurs in babies around the time of birth. Maria is interested in the health of babies before they are born and the effects of abnormal brain development in infants. Through research, she hopes to figure out new ways to help babies who are born sick.

\section{JESSIE R. MAXWELL}

Jessie R. Maxwell is a neonatologist (a doctor who specializes in the care of newborn infants) and a scientist who is dedicated to improving the long-term outcomes of babies born early or sick. During fellowship training, she realized how many babies are born who have been exposed to alcohol before birth and realized how many of these babies have long-lasting problems because of this exposure. The brains of these babies do not develop normally, and as a doctor, there is not much she can do to make the brains develop better. However, in the laboratory, she is able to work toward expanding the current information known about these babies, with the ultimate goal of finding ways to help them. *jrmaxwell@salud.unm.edu 